\title{
Impact of Non-monetary Rewards on Employees' Motivation: a Study of Commercial Banks in Karachi
}

\author{
Dr. Farooq-E-Azam Cheema* \\ Bahria University, Karachi Campus \\ Sobia Shujaat* \\ Bahria University Karachi Campus \\ Rafia Alam* \\ Bahria University Karachi Campus
}

\begin{abstract}
Purpose - This study is conducted to measure the impact of non-monetary rewards on employees' motivation in different banks in Karachi, Pakistan. The study aims to highlight importance of the non-monetary rewards in terms of their effectiveness as well as efficiency. The study also will identify to what extent the banks are taking care of this source of employee motivation. Methodology/Sampling - The study follows a quantitative approach to achieve the objectives of this study, which is descriptive in nature. There are five independent variables taken for this study; training, recognition for performance, opportunities for career advancement, effective communication channels and job security to identify their impact over employees' job related motivation. A standardized and well-structured questionnaire was used to gauge the responses on a five level scale. Questionnaire contents were adopted from Paul E. Spector employee recognition program handbook. Questionnaire was sent to 550 respondents through e-mail and in printed form. Data was analyzed using Statistical Package for the Social Sciences (SPSS). The descriptive statistics utilized was based on chi-square tests and graphical illustrations were used to provide information on key demographic variables in this study.

Findings - The study confirmed existence of positive significant relationship between three of the five non-monetary rewards. The context against which relationship of two independent variables i.e. training and performance recognition has not been found significant has been discussed in the findings.

Practical Implications - This research can be helpful for HR managers in banking sector. They can design effective compensation package to retain their competent employees. Management can improve the use of effective rewards and recognition system in the feedback process of their performance management system in order to motivate their employees.
\end{abstract}

Keywords: Non-Monetary Rewards, Recognition, Employee's Motivation, Banking sector.

Jel classification: M12, M14, 015

\footnotetext{
* The material presented by the authors does not necessarily portray the viewpoint of the editors and the management of the Institute of Business \& Technology (IBT)

*Farooq-E-Azam Cheema: dr.cheema@live.com

* Sobia Shujat: sobia@bimcs.edu.pk

* Rafia Alam: raffia.alam@gmail.com
} 


\section{INTRODUCTION}

The overall success of an organization in achieving its strategic objectives relies heavily on the motivation level of employees. All organizations, regardless of sector, size or industry require motivated workforce that ensures the efficiency, high organizational output and prosperity of the organization. De-motivated employees are likely to put in little or no effort in their jobs, produce low quality work, mostly avoid their workplace and even exit the organization if provided opportunity. On the other hand, employees who are motivated to work are likely to be determinant, innovative and competent. Motivated employees are contented, dedicated and work enthusiastic, resulting in optimum level of employee retention, loyalty and harmony. This contributes significantly to the growth and development of the overall organization.

Consequently, one of the most compelling challenges facing today's organizations is how to make sure that employees are highly motivated. Numerous studies have proved that rewarding employees is one of the best ways to keep the workforce motivated. It has been found through these studies that connection between rewards, recognition and motivation of employee are strategically significant to the success of an organization. Motivation, thus, is a factor that exerts a driving force on our actions and work. So, rewards both monetary and non-monetary seek to attract people to join an organization and keep them motivated to perform up to high levels.

This research work is also aimed to ascertain the practice of monetary and non-monetary rewards in the banking industry of Pakistan and its impact over motivation level of the employees. Banking industry is extremely competitive service sector wherein the employees are required to provide exceptional quality services to their customers. To obtain such services employees must be motivated. Accordingly, employee incentive programs have been found to be the most commonly adopted technique among many organizations. Research shows that organizations are pumping billions of dollars each year into employee incentive programs..

Next question is, 'what is reward?' research works have found out that people in the organizations are motivated by monetary and non-monetary rewards both. For example, research works of Armstrong and Murlis (1991), Schuler and Jackson, (1996) and Lai (2007) explained that total remuneration consists of financial rewards (fixed and variable) and non-financial rewards (praise, achievement, responsibility, freedom, job satisfaction, job security and personal growth etc). however, the fact remains that every employee has their individual set of motivation and incentives to expend effort. Some are motivated by money while others are motivated by recognition, career advancement or even by job security. Thus it is wrong to assume that everyone shares a common motivator.

\subsection{Hypotheses}

$\mathrm{H}_{1}$ : Providing training to the employees does not yield any motivating impact upon the employees in banks.

$\mathrm{H}_{2}$ : Providing career growth related opportunities to the employees does not yield any motivating impact upon the employees in banks.

$\mathrm{H}_{3}$ : Providing fair recognition on performance to the employees does not yield any motivating impact upon the employees in banks.

$\mathrm{H}_{4}$ : Providing effective internal communication channels does not yield any motivating impact upon the employees in banks.

$\mathrm{H}_{5}$ : Providing job security to the employees in the banks does not yield any motivating impact upon them. 


\section{LITERATURE REVIEW}

Khan and Farooq (2010) conducted a study on impact of rewards on employee motivation in Commercial Banks. The study showed a positive significant relationship between rewards and employee motivation among the employees' of commercial banks in Pakistan. According to the study findings, motivated employees are more energetic and productive on their work. When employees expect personally valued, recognized and rewarded, they undoubtedly work harder and feel motivated to accomplish their tasks. They are likely to perform way above the level expected of their capacity. According to a study by Matthew et al, (2009) there is positive connection between organization effectiveness and employee motivation. Earlier, Schuler and Jackson, (1996) had already found out that the connection between rewards, recognition and motivation of employees is strategically significant to the success of an organization.

According to a seminal study conducted by Armstrong (1988), motivation at work operates in two ways. First, people can motivate themselves by doing work that intrinsically motivates them and which leads them to expect that their goals will be achieved. Secondly, higher management can provide a motivating environment through such methods as pay and bonus schemes. He called the former the intrinsic motivation while the latter the extrinsic motivation. Intrinsic motivation is concerned with selfgenerated factors, which influence people to act in a certain way. These factors include responsibility (feeling that work is important and having control over one's resources), freedom to act, scope to use and develop skills and abilities, interesting and challenging work and opportunities for advancement and growth. Extrinsic motivation, on the other hand, is concerned with what is done to or for people to motivate them. This includes rewards such as increased pay and bonus schemes. Latter Ajila (1997) found that an intrinsically motivated individual is committed to his work to the extent to which the job inherently contains tasks that are rewarding to him. And an extrinsically motivated person is committed to the extent that he can gain or receive external rewards for his job. Ajila (1997) further suggested that for an individual to be motivated in a work situation there must be a need, which the individual would have to perceive a possibility of satisfying through some reward.

A "McKinsey Quarterly" study found that $70 \%$ of organizations are using or planning to use motivation programs for their organizations (Dewhurst et al, 2009). According to the findings of this study, for most people non-monetary rewards or recognition serve as a better motivator than money. Money alone is not always enough to motivate high performance, the study concluded. Latter, a study by Latham and Locke (2004) found that motivation can also be achieved by non-financial rewards and recognition like praise, achievement, responsibility and personal growth etc. according to the study, non-financial reward can create perceptions of the overall fairness of a rewards program which leads to employee's motivation towards their work.

Sammer (2011) coined a term "total reward" that includes career developmental opportunities, non-financial recognition, employee development and training besides monetary incentives and rewards. Earlier, Armstrong and Murlis (1991) had also talked about the same concept of total remuneration that. According to them, consists of financial rewards both fixed and variable and the non-financial rewards including verbal praise, achievement, responsibility, freedom, job satisfaction, job security and personal growth etc. likewise, Strovall (2003) argues that non-financial rewards motivate workers which lead to job satisfaction and an effective reward package could have an important impact on the employee's performance. Dzuaranin (2012) says that companies that only focus on monetary incentives to motivate their employees must also introduce nonmonetary rewards to their performance rewards systems to increase the motivation level of their employees since many people prefer the former over the latter. Thr study suggests that the organizations using effective reward programs better achieve their organizational objectives and also influence employee behavior.

In the same stream, Mason (2001) found that recognition in various forms is a powerful motivational and retention strategy for any organization. He argues that it is not expensive for any organization to adopt strategies to motivate their talented employees by recognizing their efforts. A study conducted by the US Department of Labor found that $46 \%$ of people leave their jobs because they feel unappreciated and management fails to handle this huge turnover because of not having proper employee 
rewards and recognition strategies says Robert (2005). The study found a positive relationship between rewards, recognition and motivation and concluded that good reward and recognition system contributes to employee motivation and satisfaction. More highly the employees would be rewarded and recognized, the more they will be motivated - and motivated employees are less likely to quit the job, the study concluded.

Wiscombe (2002) conducted a research with managers and revealed that recognizing employees assists them to become more productive. According to this study, $69.3 \%$ of the respondent managers indicated that providing non-monetary recognition helps more the manager to achieve their organizational goals. A survey by the Professional Secretaries International revealed that $30 \%$ of professional secretaries prefer a simple letter of appreciation from their managers. However, only $7 \%$ had got such letters in their career. The finding bespeaks indifference of the organizations towards such effective and efficient source of employee motivation on the job.

\section{RESEARCH METHOD}

In order to test the hypotheses, quantitative study was conducted and descriptive analysis technique was used. Two independent variables, non-monetary rewards and recognition were taken to ascertain their impact over motivation level of the employees - dependent variable. Survey method was employed to collect data from different banks of Karachi. Name of banks are not mentioned here because of confidential issues. Total population of this study was unknown; hence a convenience based sample of 384 was selected for this study. All respondents belonged to different managerial levels such as branch managers, operation managers, credit officers, finance and trade officers.

A standardized and well-structured questionnaire was used to gauge the responses on a five level Likert scale ranging from strongly agree to strongly disagree options. Questionnaire contents were adopted from Paul E. Spector (1988) and "Employee recognition program handbook" developed by department of human resource management of Virginia (2000). Questionnaire was sent to the respondents through e-mail and in printed form.

Data was analyzed using Statistical Package for the Social Sciences (SPSS). The descriptive statistics utilized was based on chi-square tests and graphical illustrations were used to provide information on key demographic variables in this study.

\section{DATA ANALYSIS}

In order to test the research hypothesis, the Pearson's product moment chi-square and graphs were used between non-monetary rewards and motivation. In order to test the research hypothesis, first Chi-square test was performed to determine if bank gives an opportunity for training to improve job-related skills and knowledge it will be source of motivation to employees to put more efforts in their jobs.

The probability of chi-square test statistics for opportunity for training to improve jobrelated skills and knowledge proved to be $p=0.120$, that is greater than the alpha level of significance that is 0.05 . Data are summarized in the Table 1 below:

Table-1: Chi-Square tests between skill training and motivation

\begin{tabular}{|l|c|c|c|}
\hline & Value & Df & A symp. Sig. (2-sided) \\
\hline Pearson Chi-Square & $22.787^{\mathrm{a}}$ & 16 & .120 \\
Likelihood Ratio & 26.144 & 16 & .052 \\
Linear-by-Linear Association & 1.407 & 1 & .235 \\
N of Valid Cases & 384 & & \\
\hline
\end{tabular}

It means there was found an insignificant relationship between opportunities for training regarding job-related skills and employee's motivation level. So the null hypothesis that 
non-monetary rewards do not have any significant positive impact on employees' motivation is accepted.

Regarding other four non-monetary incentives namely employee's participation in career development activities, positive working environment for employees, flexible office hours and opportunities to promotion were found having positive impact on employee's motivation. The probability of Chi-square test statistics for all these four factors is less than the alpha level of significance of 0.05 that shows their significant relationship with motivation. Findings of the test are summarized in the Table 2 below:

Table-2: Chi-Square tests between career advancement opportunities and motivation

\begin{tabular}{|l|c|c|c|}
\hline & Value & Df & Asymp. Sig. (2-sided) \\
\hline Pearson Chi- & $45.372^{\mathrm{a}}$ & 16 & .000 \\
Square & 30.690 & 16 & .015 \\
Likelihood Ratio & .200 & 1 & .655 \\
Linear-by-Linear & & \\
sociation & 384 & & \\
N of Valid Cases & & \\
\hline
\end{tabular}

Table 2 above shows that there is a statistically significant association between employee's participation in career development activities and their motivational level. The probability of Chi-square test statistic (Chi-square $=45.372$ ) is $p=0.000$, that is less than the alpha level of significance of 0.05 . Thus, the null hypothesis that opportunities for career advancement do not have any significant positive impact on employees' motivation is rejected.

Pearson chi-square was also calculated between recognition for performance and employees' motivation to perform better. The values were summarized in the Table 3:

Table-3: Chi-Square tests between fair recognition and motivation

\begin{tabular}{|l|c|c|c|}
\hline & Value & Df & $\begin{array}{c}\text { A symp. Sig. } \\
\text { (2-sided) }\end{array}$ \\
\hline $\begin{array}{l}\text { Pearson Chi- } \\
\text { Square }\end{array}$ & $14.887^{\mathrm{a}}$ & 16 & .533 \\
$\begin{array}{l}\text { Likelihood Ratio } \\
\text { Linear-by-Linear }\end{array}$ & 16.528 & 16 & .417 \\
$\begin{array}{l}\text { Association } \\
\text { N of Valid Cases }\end{array}$ & 3.427 & 1 & .064 \\
\hline
\end{tabular}

The probability of chi-square test statistics (Chi-square $=14.887$ ) was found $p=0.533$, that is greater than the alpha level of significance of 0.05 . it shows there was found an insignificant relationship between equal recognition to every team member and employee's motivation level. Thus, the null hypothesis that due performance recognition does not have any significant positive impact on employees' motivation is accepted. Chi-square test was also performed to determine effect of banks' internal communication channel over the employees' motivation to perform better on their job. Values of the findings are summarized in the Table 4. 
Table-4: Chi-Square tests between effective internal communication and motivation

\begin{tabular}{|l|c|c|c|}
\hline & Value & Df & $\begin{array}{c}\text { A symp. Sig. } \\
\text { (2-sided) }\end{array}$ \\
\hline Pearson Chi-Square & $31.108^{\mathrm{a}}$ & 16 & .013 \\
Likelihood Ratio & 36.431 & 16 & .003 \\
Linear-by-Linear & .946 & 1 & .331 \\
$\begin{array}{l}\text { Association } \\
\text { N of Valid Cases }\end{array}$ & 384 & & \\
\hline
\end{tabular}

As per the Table 4, the probability of Chi-square test statistic (Chi-square $=31.108$ ) is $\mathrm{p}$ $=0.013$, that is less than the alpha level of significance of 0.05 . The data indicate a significant relationship between internal communication channel and employee's motivation level. Thus the null hypothesis that effective internal communication channels do not have any significant positive impact on employees' motivation is rejected.

For the Chi-square test conducted to determine effect of job security available to the bank employees on employees' motivation findings were as follow:

Table-5: Chi-Square tests between Job security and motivation

\begin{tabular}{|l|c|c|c|}
\hline & Value & Df & $\begin{array}{c}\text { A symp. Sig. } \\
\text { (2-sided) }\end{array}$ \\
\hline Pearson Chi-Square & $96.245^{\mathrm{a}}$ & 16 & .000 \\
Likelihood Ratio & 88.591 & 16 & .000 \\
Linear-by-Linear & 51.672 & 1 & .000 \\
Association & 384 & & \\
N of Valid Cases & & & \\
\hline
\end{tabular}

The probability of Chi-square test statistic (Chi-square $=96.245$ ) is $p=0.000$, that is less than the alpha level of significance of 0.05 . This shows that there is a statistically significant association between job security and employee's motivational level. It means if employees feel their job secure then this job security will greatly impact on employee's motivational level. Thus, the null hypothesis that effective recognition does not have any significant positive impact on employees' motivation is rejected.

\section{CONCLUSION}

Most of the results of the study are in accordance with the hypotheses. Although two factors; providing opportunity of training and fair recognition of the efforts on the job could not find a significant relationship with the employees' job related motivation. This shows that employees are less likely to be motivated through banks' training and recognition related interventions and endeavours. Chi-square test found a significant relationship between opportunities for career advancement and employee's motivation level supporting the research of Jenkins and Adrian Giles, (2012) that employees though value verbal praise and recognition from their managers, they are more motivated by promotion and career development opportunities.

There is also found a significant relationship between effective internal communication channels and employees' job related motivation level. These findings are in line with the findings of the research carried out by M. Ashfaq et al (2012) on the 
role of effective communication in retention and motivation of employees. The results of that work showed that workers consider effective communication very important to their motivation and vital source of their association with the organization. According to the results of our study communication gives the feeling of belonging and sense of partnership with employees working in the organization. When employees feel that they have been heard and that they can communicate with their supervisors whenever they need they feel themselves more a part of the group and, in the result, are more motivated to work.

On the other hand, verbal praise of appreciation from management in front of colleagues, feeling of being valued in the bank, a positive working environment, encouragement by upper management on new initiatives, effective internal communication, gaining respect and good relationship with other co-workers, proper and correct appraisal of employee by management are motivating factors for employees of different banks of Karachi. Out of five factors, only one factor i.e. opportunity for training to improve job-related skills and knowledge is insignificant. Hence, both null hypothesis of this study are being rejected and Alternative hypothesis i.e. Non-monetary rewards and effective recognition has a significant positive impact on employees' motivation in banks in Karachi, Pakistan is supported by this study. Finally, it has been concluded that non-monetary rewards and recognition have a positive and significant impact on employee's motivation among bank employees in Karachi.

Findings of this show that opportunity for training has insignificant relationship with employee's motivation to put more efforts in their job. Whereas, studies of Farhan et al (2011) we referred to in the literature review found training and development having positive and significant association with employee's motivation of banks in Pakistan. The reason behind insignificant association between training and employees' motivation may be that offering job and skills related training to the employees may cause a feeling of insecurity among them. They may feel bank takes them incompetent that results in training to them.

Likewise, findings of this study also an insignificant relationship between recognition of contribution of the employees by the supervisors and employees' motivation level. This insignificant association is because it creates negative feeling among bank employees that every individual in a team whether he/she contributes significantly or not. This feeling is likely to de-motivate the talented and hardworking employees who could stop working hard if all people are recognized equally regardless of level of their contribution.

In this area of study future research suggestion to examine the combined effect of financial and non-financial job rewards on employee's motivation with the moderating demographic differences like age and gender. Using age and gender difference as moderating variables, the effect of non-monetary rewards on the employees' motivation can be further refined keeping in view their preferences for particular rewards.

\section{REFERENCES}

1. Ajila, C.O. (1997). Job Motivation and Attitude to Work as Correlates of Productivity among Workers in Manufacturing Companies in Lagos State. Nigeria. Unpublished Ph.D Thesis submitted to the Department of Psychology O.A.U Ile IfeOsun State, Nigeria.

2. American Psychological Association. (2012). "Feeling Valued at Work Linked to Well-Being and Performance", APA Survey Report (2012), United States, APA.

3. Armstong, Michael. (1977), Human Resource Management Practice, 7th edition. Great Britan: Kogan Page Limited, pp.922.

4. Armstrong, M., \& Murlis, H. (1991). Reward management. London: Kogan Page Ltd.

5. Baron, R.A. (1983). Behavior in organizations. New York: Allyn \& Bacon, Inc.

6. Calista Lai, (2009). Motivating employee's through incentives programs. Bachelor's thesis, school of business administration, JYVÄSKYLÄ University of Applied Science. 
7. Dzuaranin, S. (2012). The effect of tangible and intangible noncash rewards on performance and satisfaction in production setting. Management Accounting Quarterly, Vol.13. (4).

8. Employee Retention Tips. Available from: <http://http://www.workplacecommunication.com/employee-retention-tips.html >.

9. Eunice Parisi-Carew, Lily Guthrie. (2009), "Creating a Motivating Work Environment", Ken Blanchard Companies.

10. Impact of Workforce Motivation on Operational Loses. (2011). StudyMode.com. Retrieved 11, 2011, from http://www.studymode.com/essays/Impact-OfWorkforce-Motivation-On-Operational-834691.html.

11. Jenkins, Adrian Giles. (2012), "The Value of Verbal Praise and Recognition amongst New Zealand Library Staff', VICTORIA, University of Willington.

12. Kaleem Ullah Khan, Syed Umar Farooq, Zilakat Khan. (2010). A Comparative Analysis of the Factors Determining Motivational Level of Employees Working in Commercial Banks in Kohat, Khyber Pukhtunkhwa. International Journal of Business and Management, Vol.5 (12).

13. Lai, C. (2009), Motivating Employees through Incentive programs, Dissertation Thesis of Bachelor Degree, Jyvaskyla University of Applied Sciences, retrieved from:

https://publications.theseus.fi/bitstream/handle/10024/17561/jamk_1237444488_5. pdf?sequence=2, (Accessed on: 11/09/2011)

14. Latham, G. P. and Locke, E. A. (2004): "What should we do about motivation theory? Six recommendations for the twenty-first century", Academy of Management Review, Vol. 29 (3), pp.388-403.

15. Martin Dewhurst, Matthew Guthridge, and Elizabeth Mohr. (2009), ' Motivating people: Getting beyond money', McKinsey Quarterly. Available from: [November 2009].

16. Mason, G. S. (2001) A three component conceptualization of organizational commitment. Human Resource Management Review, Vol. 1, (11), pp. 61-89.

17. Matthew, J., Grawhich, \& Barber, L. K., (2009). Are you focusing both Employees and Organizational Outcomes Organizational Health Initiative at Saint Louis University (ohi.slu@edu), 1-5.

18. M. Ashfaq, Kashif, Nadeem, and Asad. (2012), "Role of Effective Communication in Retention and Motivation of Employees", ICABSEI, pp. 64-67.

19. M. Farhan, Khizer A., Shama Sadaqat, Shoaib H. (2011), "Extent of training in Banks and its Impact on employees motivation and involvement in job", Interndisciplinary journal of contemporary research in business, Vol. 2(12), pp. 793.

20. Roberts. (2005). relationship between rewards, recognition and motivation at an insurance company in the Western Cape.

21. Schuler, R.S., and Jackson, S.E. (1996). Human Resource Management: Positioning for the 21st Century. (6 ${ }^{\text {th }}$ ed.), New York: West Publishing Company.

22. Sekaran, U. (2003). Research Methods for Business a Skill Building Approach (4th end). New York: John Wiley, pp. 292-297.

23. Stephenson, S. (1995). Incentive programs: Is holding a fistful of dollars enough? Restaurants \& Institutions, Vol. 105 (14), pp. 110.

24. Stovall. (2003). increasing employee participation in fire safety education programs using non-monetary rewards.

25. Wiscombe (2002), "Recognition and Performance Link", Workforce, pp. 44. 